\title{
Genetic mapping of a cone and rod dysfunction (Åland Island eye disease) to the proximal short arm of the human $\mathrm{X}$ chromosome
}

\author{
I A Glass, P Good, M P Coleman, P Fullwood, M G Giles, S Lindsay, A H Nemeth, \\ K E Davies, H A Willshaw, A Fielder, M Kilpatrick, P A Farndon
}

Department of

Pediatrics, School of

Medicine, University of California, San

Francisco, CA 94143,

USA.

I A Glass

Department of
Ophthalmology,
University of
Birmingham,
Birmingham and
Midland Eye Hospital,
Church Street,
Birmingham B3 2NS,
UK.
P Good
H A Willshaw
A Fielder

Institute of Molecular

Medicine, John

Radcliffe Hospital,

Oxford, UK.

M P Coleman

A $\mathrm{H}$ Nemeth

K E Davies

Genetics Unit,

University of

Birmingham,

Birmingham

Maternity Hospital,

Birmingham, UK.

P Fullwood

M G Giles

M Kilpatrick

P A Farndon

Division of Human

Genetics, University of

Newcastle, Newcastle

upon Tyne, UK.

$S$ Lindsay

Correspondence to

Dr Good.

Received 8 February 1993.

Revised version accepted

2 July 1993.

\begin{abstract}
A five generation family with an $\mathrm{X}$ linked ocular disorder has been investigated. The major clinical features were reduced visual acuity, nystagmus, and myopia. Although impaired night vision was not a symptom, using psychophysical and electrophysiological testing both rod and cone function were found to be abnormal in all affected males. No abnormality was detected in carrier females. Gene location studies showed $X$ linked transmission of a gene that maps to proximal Xp11.

The findings observed in this cohort are similar to those previously reported in both congenital stationary night blindness type 2 (CSNB2) and Åland Island eye disease (AIED). This study addresses whether CSNB2 and AIED are a single entity or whether the latter is a subset of the former.

(f Med Genet 1993;30:1044-50)
\end{abstract}

About 15 years ago, Krill ${ }^{1}$ suggested that two inherited ocular disorders, Alland Island eye disease (AIED) and congenital stationary night blindness (CSNB), might be a single entity. Åland Island eye disease or ForsiusEriksson syndrome (MIM 300600) is an X linked eye disorder so far reported in two apparently unrelated Scandinavian families. ${ }^{23}$ This non-progressive condition is characterised by reduced visual acuity, reduced dark adaptation, colour vision abnormalities, infantile nystagmus, and high axial myopia.

Table 1 Comparison of the clinical findings reported in CSNB1 and CSNB2.

\begin{tabular}{lcc}
\hline Clinical findings & $\begin{array}{c}\text { CSNB1 } \\
\text { (complete) }\end{array}$ & $\begin{array}{c}\text { CSNB2 } \\
\text { (incomplete) }\end{array}$ \\
\hline Visual acuity & Reduced & Reduced \\
Night blindness & + & +- \\
Nystagmus & +- & +- \\
Dark adaptation-rod & Absent & Raised \\
Colour vision & +- tritanopia & $\begin{array}{c}\text { by } 1.0 \text { to } 1.5 \text { log units) } \\
+/ \text { tritanopia }\end{array}$ \\
Visual field & Myopia & Normal \\
refraction & Varied \\
Fundus appearance & (moderate to high) & (hyperopia to myopia) \\
Rod ERG & Absent & Normal/hypopigmented \\
Cone ERG & Subnormal \\
Oscillatory potentials & Normal or subnormal & Reduced \\
EOG & Reduced & Intact \\
\hline & Normal & Normal \\
\hline
\end{tabular}

Initially, AIED was thought to be a variant of ocular albinism, primarily on the basis of the fundal depigmentation in the original family. ${ }^{2}$ This has subsequently been disproved as there is no demonstrable visual pathway misrouting ${ }^{4}$ and macromelanosomes are not present in the skin of affected males or carrier females. Furthermore, Waardenburg ${ }^{5}$ re-examined the original family and considered that the fundal appearance with multiple areas of focal depigmentation was not typical of albinism. In AIED female carriers are normal on clinical and electrophysiological examination (although two carrier females had slight latent nystagmus, ${ }^{6}$ and this is one feature which distinguishes this condition from $\mathrm{X}$ linked progressive cone dystrophy. ${ }^{7}$

Congenital stationary night blindness is a group of disorders with the common features of reduced visual acuity, impaired dark adaptation, and infantile nystagmus. The major clinical and electrophysiological features are shown in table 1 and fig 1 . All types of CSNB exhibit a characteristic negative ERG to a white flash under scotopic conditions. This is termed the Schubert-Bornshein response, ${ }^{8}$

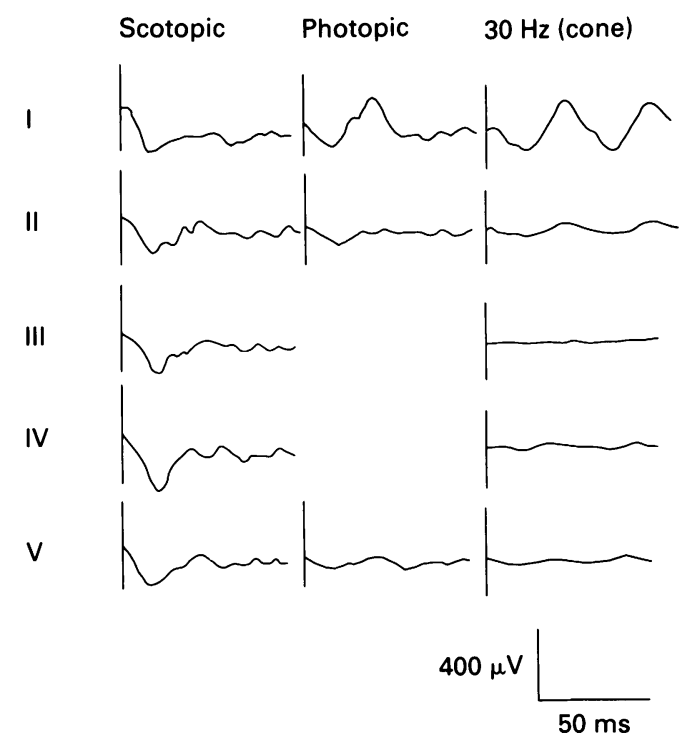

Figure 1 Representative scotopic ERGs for comparison purposes. I CSNB1. ${ }^{12}$ II CSNB2. ${ }^{12}$ III AIED. ${ }^{1}$ IV AIED. ${ }^{2} V$ This study. 
and is characterised by a normal a wave but reduced $b$ wave (with or without a rod/cone separation of the $b$ wave). There are two types of CSNB depending on whether the rod deficit is complete or incomplete, where the terms complete CSNB (CSNB1) or incomplete CSNB (CSNB2) are used respectively. Cone function is always affected in CSNB2, but is infrequently affected in CSNB1. In CSNB2, since some patients have some residual rod function, night blindness may not be a symptom, although defective dark adaptation can always be shown on formal testing. These tests also show residual rod function which cannot be detected in CSNB1.

The two types of CSNB appear unlikely to be allelic on clinical grounds as no single family has contained both forms. This is consistent with the hypothesis that the fundamental defect lies in the inner photoreceptor segment in CSNB1, while in CSNB2 it is in the bipolar cell layer of the retina. This assertion that CSNB1 and CSNB2 are aetiologically distinct has been disputed on electrophysiological criteria ${ }^{9}$ but, as Musarella ${ }^{10}$ and Myake et $a l^{8}$ point out, the lack of methodological ERG standardisation precludes making any valid conclusion on this issue. Although Khouri et $a l^{11}$ reported both conditions in one family it is now considered that all members of this family had CSNB2. ${ }^{12}$ Assignment of the gene responsible for CSNB2 is awaited and may facilitate clarification of possible allelism to $\mathrm{X}$ linked CSNB1 which appears to map to $\mathrm{Xp} 11 .{ }^{13-15}$
The basic defect in either CSNB2 or AIED has not been elucidated but the two conditions have been suggested to be clinically indistinguishable. ${ }^{1312}$

To explore the hypothesis that CSNB2 and AIED are a single entity we have recently ascertained and investigated a large five generation family with an $\mathrm{X}$ linked cone and rod disease, and undertaken a gene mapping investigation.

\section{Methods}

\section{FAMILY STUDY}

The family with 10 affected males and 12 obligatory carriers was ascertained after genetic counselling was sought following the presentation of $\mathrm{V} \cdot 2$ with congenital nystagmus and markedly impaired visual acuity. A pedigree depicted in fig 2 was constructed and information obtained from family members, ophthalmologists, and family doctors. Detailed ophthalmological examination and investigation was performed on six adult males and two obligate carriers. The examination consisted of cycloplegic refraction, slit lamp examination, indirect ophthalmoloscopy, fundal photography, and electroretinography.

Visual fields were measured with a Goldman perimeter. Colour vision was assessed using the Farnsworth panel D-15 test. Dark adaptation (binocular) was measured using the integral technique of Goldmann-Weekers. Preadaptation was achieved at $650 \mathrm{~cd} / \mathrm{m}^{2}$ and the

$\begin{array}{lll} & \text { DMD } & \text { A,B } \\ \text { DXS228 } & 1,2,3 \\ \text { PFC } & 5,6,7 \\ \text { DXS255 } & \text { C,D,E,F } \\ \text { DXS14 } & 8,9 \\ & \text { DXS566 } & \text { F,G,H }\end{array}$
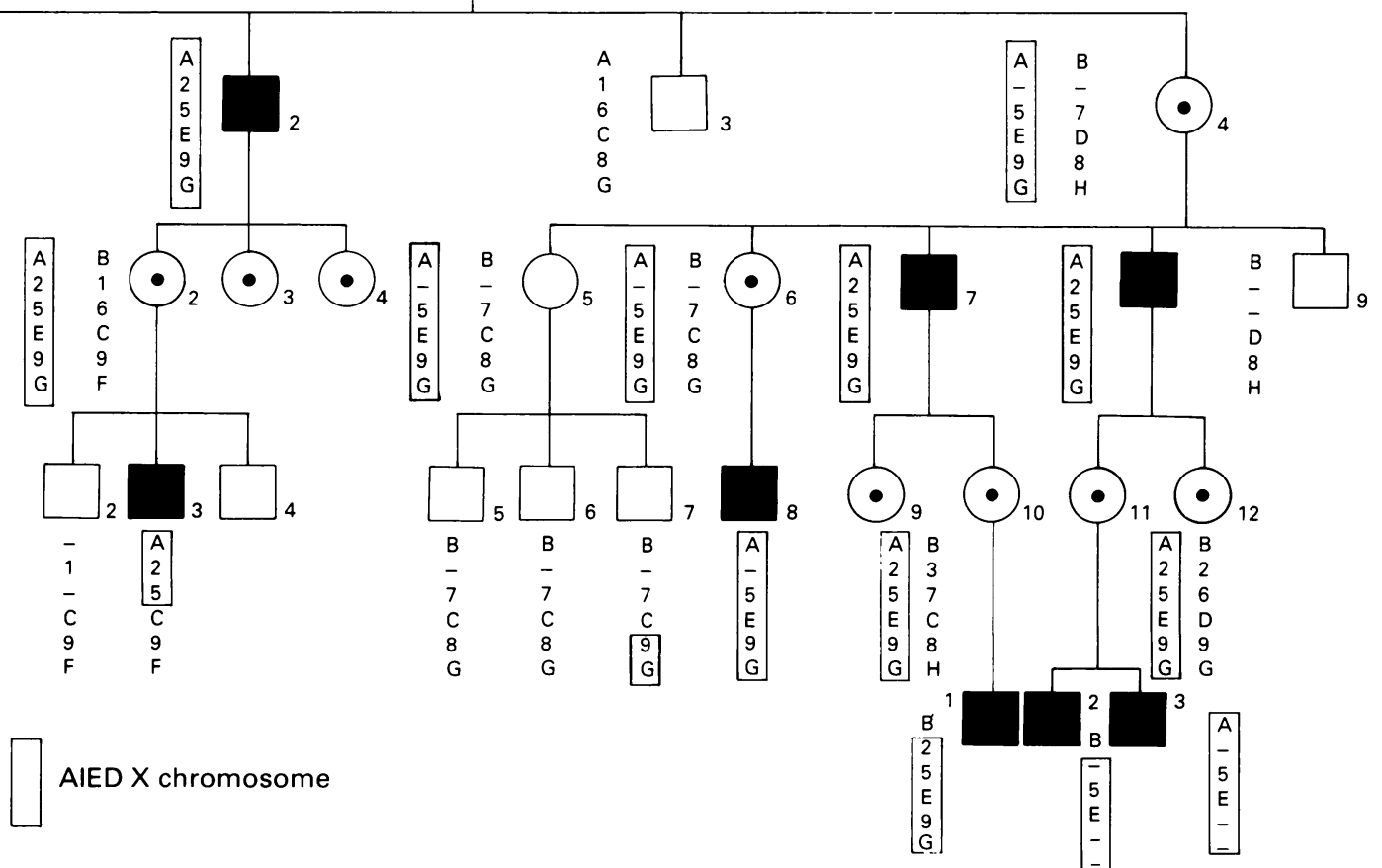

Figure 2 Recombination events with DNA loci from Xp21 to Xq13. The affected X chromosome is outlined and inferred genotypes are bracketed for subjects $I-1$ and I-2. A dash (-) indicates no typing information available at that locus. 
Table 2 Details of ophthalmological assessment of family members.

\begin{tabular}{|c|c|c|c|c|c|c|c|c|c|c|}
\hline \multirow[t]{2}{*}{ Patient } & \multirow[t]{2}{*}{ Age } & \multirow[t]{2}{*}{ Nystagmus } & \multicolumn{2}{|c|}{ Visual acuity } & \multicolumn{2}{|c|}{ Refraction } & \multirow[t]{2}{*}{ Astigmatism } & \multirow[t]{2}{*}{ Nyctalopia } & \multirow{2}{*}{$\begin{array}{c}\text { Dark adaptation } \\
\text { threshold } \\
\text { (normal } \\
<100 \mathrm{Asb})\end{array}$} & \multirow{2}{*}{$\begin{array}{c}\text { Colour } \\
\text { deficiency }\end{array}$} \\
\hline & & & $\mathbf{R}$ & $\mathrm{L}$ & $\mathbf{R}$ & $\mathrm{L}$ & & & & \\
\hline $\begin{array}{l}\text { III } \cdot 7 \\
\text { III } \cdot 8 \\
\text { IV·3 } \\
\text { IV } 8 \\
\text { V } 1 \\
\text { V·2 } \\
\text { V·3 } \\
\text { III } 6 \\
\text { IV } 11\end{array}$ & $\begin{array}{l}46 \\
49 \\
10 \\
23 \\
3 \\
4 \\
2 \\
40 \\
24\end{array}$ & $\begin{array}{l}+ \\
+ \\
+ \\
+ \\
+ \\
+ \\
+ \\
- \\
-\end{array}$ & $\begin{array}{c}6 / 18 \\
6 / 12 \\
6 / 24 \\
6 / 36 \\
6 / 12 \\
6 / 9 \\
6 / 6 \\
6 / 18 \\
\text { (ambyl }\end{array}$ & $\begin{array}{c}6 / 24 \\
6 / 18 \\
6 / 24 \\
6 / 36 \\
6 / 12 \\
6 / 9 \\
\\
6 / 6 \\
6 / 9 \\
\text { teye) }\end{array}$ & $\begin{array}{c}-16 \\
-10.5 \\
-17.5 \\
-30 \\
-4 \\
-3 \\
-6.5 \\
-0.25 \\
+7.5\end{array}$ & $\begin{array}{c}-16 \\
-9.5 \\
-17.5 \\
-30 \\
-3 \\
-3.5 \\
-7 \\
+0.25 \\
+0.5\end{array}$ & $\begin{array}{l}+ \\
+ \\
+ \\
+ \\
+ \\
+ \\
+ \\
+ \\
-\end{array}$ & $\begin{array}{l}- \\
- \\
- \\
- \\
- \\
- \\
- \\
-\end{array}$ & $\begin{array}{c}631 \\
800 \\
\text { No data } \\
315 \\
\text { No data } \\
230 \\
\text { No data } \\
27 \\
63\end{array}$ & $\begin{array}{c}\text { Tritanopia } \\
\text { Tritanopia } \\
\text { No data } \\
\text { Tritanopia } \\
\text { No data } \\
\text { No data } \\
\text { No data } \\
\text { Normal } \\
\text { Normal }\end{array}$ \\
\hline
\end{tabular}

course of dark adaptation was followed for 20 to 25 minutes, measuring threshold values with short intervals.

Dark adapted full field electroretinography (ERG) was performed on both eyes under the following conditions: pupillary dilatation, dark adaptation for 20 minutes, application of carbon fibre electrodes to the cornea referred to $\mathrm{Ag} / \mathrm{AgCl}$ disc electrodes at the outer canthus. A common ground electrode was placed on the forehead, and electrode resistance was maintained below $5 \mathrm{k}$ ohm. Filter band width was 1 to $2000 \mathrm{~Hz}$. The stimulus consisted of single blue/white flashes $(480 \mathrm{~nm})$ having an intensity of 35 foot lamberts. Oscillatory potentials were obtained using a stimulus intensity of 70 foot lamberts with a band pass filtering of 100 to $2000 \mathrm{~Hz}$. The photopic ERG and cone $(30 \mathrm{~Hz})$ flicker responses were obtained after light preadaptation ( 70 foot lamberts) for 10 minutes using the blue/white light of intensity 70 foot lamberts (photopic) or 17.5 foot lamberts (flicker). Visual evoked responses (VERs) were obtained to diffuse blue/white flash and $2 \cdot 3$ cycles per degree pattern appearance checquerboard using the Apkarian technique $^{16}$ to identify any misrouting of the visual pathways.

\section{DNA POLYMORPHISM ANALYSIS}

Blood was obtained for DNA extraction from 28 subjects including nine affected males, six normal males, 10 obligate carriers, and one female of unknown status. ${ }^{17}$ RFLP analysis was performed by either DNA hybridisation, ${ }^{18}$ or by PCR amplification followed by restriction enzyme digestion. ${ }^{19} \mathrm{CA}$ repeat analysis was performed as outlined in Weber and May. ${ }^{20}$ Details of the DNA polymorphisms are from Williamson et $a l^{21}$ apart from DXS566 22 and $\mathrm{RC} 12$ (this paper).

A CA repeat was isolated from cosmid $\mathrm{RC12}$. This cosmid was isolated using an end clone of a $640 \mathrm{~kb}$ YAC containing DXS7,

Table 3 Retrospective details of ophthalmological assessments of IV.8.

\begin{tabular}{lcccc}
\hline $\begin{array}{l}\text { IV.8 } \\
\text { age }\end{array}$ & Nystagmus & $\begin{array}{c}\text { Visual acuity } \\
\text { (bilateral) }\end{array}$ & \multicolumn{2}{c}{ Refraction } \\
\cline { 4 - 5 } & & & $\mathrm{R}$ & $\mathrm{L}$ \\
\hline 2 & - & $6 / 12$ & -9 & -8 \\
6 & - & $6 / 12$ & -12 & -11 \\
7 & - & $6 / 24$ & \multicolumn{2}{c}{ No data } \\
10 & - & $6 / 60$ & -14 & -14 \\
15 & - & $6 / 60$ & -15 & -15 \\
23 & + & $6 / 36$ & -30 & -30 \\
\hline
\end{tabular}

MAO-A, MAO-B, and NDP and maps approximately $250 \mathrm{~kb}$ proximal to $\mathrm{MAO}-\mathrm{A}$. Primers were designed to flank the CA repeat: 5' CTG TGA GGG ACA GGG TGT A3' $5^{\prime}$ TCT CAG CTT CCA TAA TTG CTC $3^{\prime}$. At least two alleles were identified. Sequence data from this article have been deposited with the EMBL/GenBank Data libraries under the Accession number X69634HFCA.

\section{LINKAGE ANALYSIS}

Computations were performed on an IBM AT personal computer. The data were compiled using the Linksys programme $\mathrm{e}^{23}$ and subjected to two point analysis using LIPED.${ }^{24}$ Assumptions for the linkage analysis included a fully penetrant mutant gene with a frequency of 0.0001 and only females known to be obligate carriers were assigned definite carrier status.

\section{Results}

FAMILY STUDY

Nystagmus was detectable in eight out of nine males. None of the affected males experienced photophobia. A mildly albinoid fundus was observed in three males but a skin biopsy from one of these males showed normal melanocytes without giant macromelanosomes. Iris transillumination was not present and the foveal reflex was considered normal. Fundal examination showed no signs of peripapillary myopic degeneration in any of the affected males. Visual fields were normal. Details of the affected males and carrier females who were available for detailed ophthalmological assessment are summarised in table 2 . Table 3 shows the records of previous ophthalmological assessments on IV. 8 over some 20 years.

Although none of the males complained of impaired nocturnal vision dark adaptation was abnormal in the four males tested (fig 3) although final adaptation levels were attained within 20 minutes in all four males. The dark adaptation threshold details are listed in table 2. In three out of four affected males an abnormal cone-rod transition zone was recorded (fig 3 ) and in all four raised rod thresholds were recorded (table 2 ).

Dark adapted (scotopic) ERGs showed a slightly reduced monophasic a wave together with a selective reduction and delay of the $b$ wave which showed subtotal loss of the oscillatory potentials (fig 1 ). The a wave amplitudes ranged from $110 \mu \mathrm{V}$ to $200 \mu \mathrm{V}$ (control $300 \mu \mathrm{V}$ ). The $\mathrm{b}$ wave amplitudes ranged from 
$40 \mu \mathrm{V}$ to $70 \mu \mathrm{V}$ (control $450 \mu \mathrm{V}$ ). No correlation was apparent between the degree of the myopia and the severity of the ERG abnormalities in the affected males (fig 4, and table 2). The light adapted (photopic) ERG from affected males was also grossly reduced for both a waves ( 5 to $30 \mu \mathrm{V}$, control $150 \mu \mathrm{V}$ ) and b waves ( 7 to $60 \mu \mathrm{V}$, control $200 \mu \mathrm{V}$ ) and oscillatory potentials were again diminished. Another ERG finding was a gross reduction of the cone stimulated responses ( $30 \mathrm{~Hz}$ flicker). The cone b wave ranged from $0 \mu \mathrm{V}$ to $20 \mu \mathrm{V}$ (control $150 \mu \mathrm{V}$ ) (fig 4).

Fig 1 illustrates the scotopic ERGs from examples of $\mathrm{CSNB} 1,{ }^{8} \mathrm{CSNB} 2,{ }^{8} \mathrm{AIED}^{2}{ }^{2}$ a

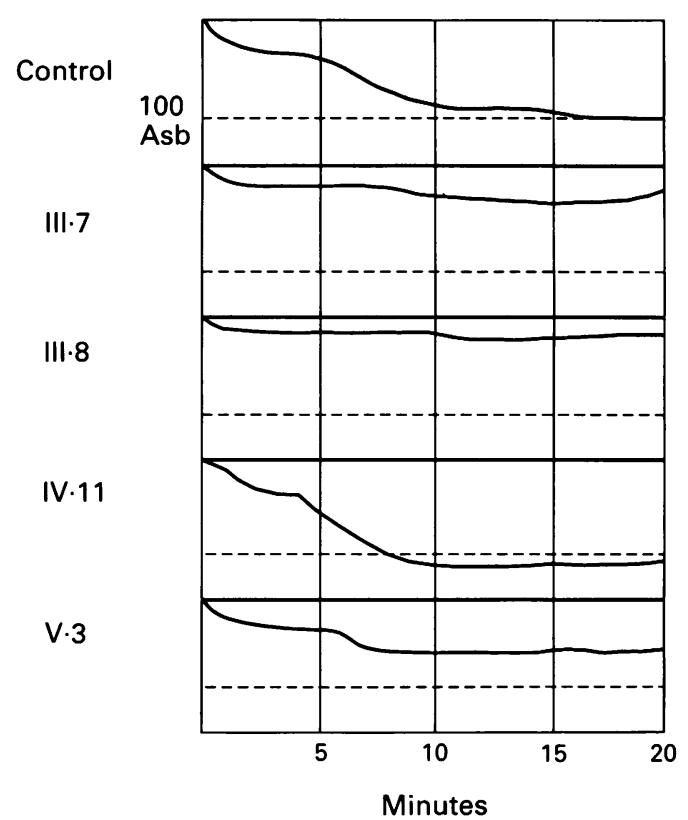

Figure 3 Dark adaptation curves of affected males.

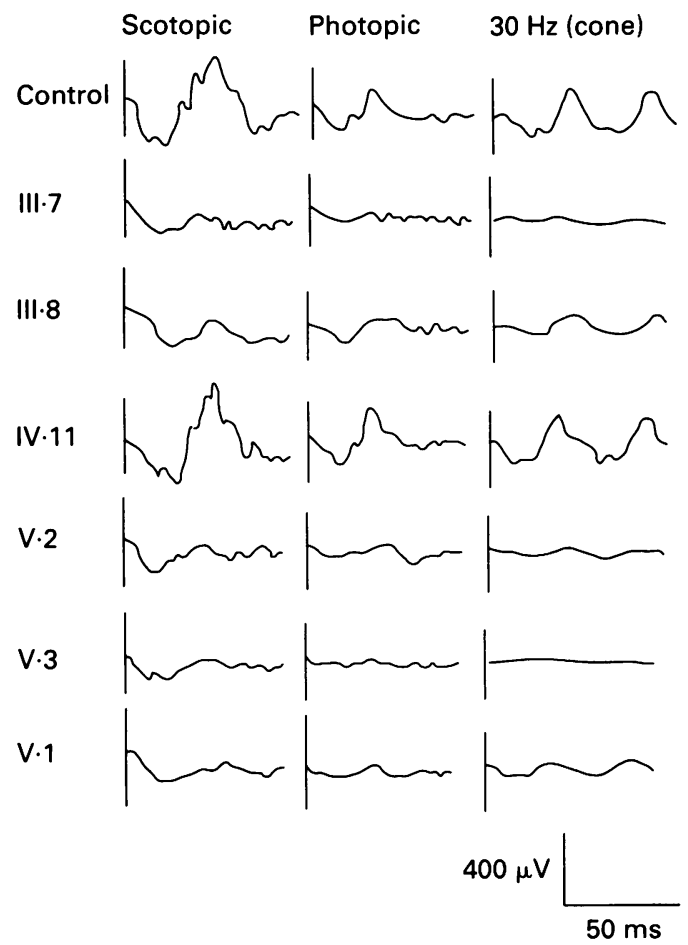

Figure 4 Scotopic, photopic, ficker ERGs of affected males and a carrier female. putative AIED family, ${ }^{3}$ and our own data for comparison purposes (table 1).

The VERs showed no evidence of misrouting or contralaterality. However, in the four males studied by this method visual evoked responses were reduced in amplitude indicating some loss of function of the central visual pathways. The VERs are depicted in fig 5.

All investigations on the carrier females were normal, two (III·6, IV·11) being available for detailed assessment.

\section{LINKAGE ANALYSIS}

The two point linkage data for AIED and 17 informative loci from the $\mathrm{X}$ chromosome are depicted in table 4. This indicates positive lod scores in $\mathrm{Xp} 11$, with significantly negative lod scores computed for loci from distal $\mathrm{Xp}$ and $\mathrm{Xq}$. The uninformative or minimally informative loci were: DXS72, DXS268, DXS1, DXS7, PGK1(CA), DXYS2, DXS178, DXS88, DXYS12, DXYS1, F9, DXS159, DXS94, DXS143, DXS31, DXS106, DXS268, DXS11.

Fig 2 illustrates the haplotypes depicting the phase known recombinants for loci derived from Xp21.3 to Xq13. IV.3 is recombinant for (DXS255, DXS566)-X-(AIED, DXS288, PFC, DMD). $\mathrm{V} \cdot 1$ and $\mathrm{V} \cdot 2$ are phase known recombinants for DMD-X-(AIED, PFC, DXS255). In addition the woman of unknown carrier status (III.5) has inherited the same haplotype as her carrier sister and therefore her normal son IV. 7 most likely represents a DXS14-X-(AIED, DXS255, PFC, DXS228, DMD) crossover.

III. 8

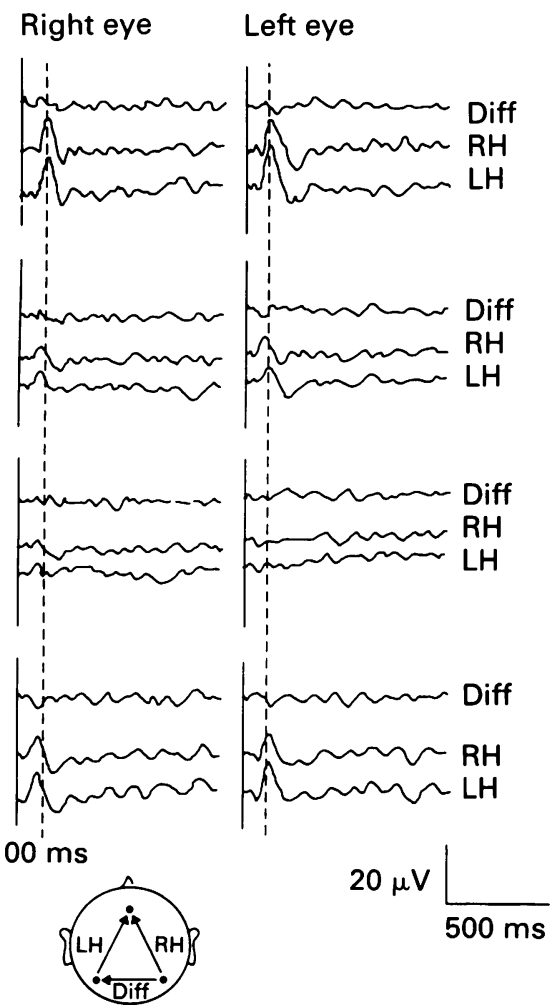

Figure 5 Visual evoked responses of affected males. 
Table 4 Two point lod scores of AIED locus versus marker loci.

\begin{tabular}{|c|c|c|c|c|c|c|c|c|c|c|}
\hline \multirow{2}{*}{$\begin{array}{l}\text { Locus/DNA } \\
\text { polymorphism }\end{array}$} & \multirow[t]{2}{*}{ Location } & \multicolumn{9}{|c|}{$\theta$} \\
\hline & & 0.00 & 0.001 & 0.05 & $0 \cdot 10$ & $0 \cdot 20$ & $0 \cdot 30$ & $0 \cdot 40$ & $Z \max$ & $\theta$ \\
\hline DXS41/99-6 & $\mathrm{Xp} 22.1$ & $-x$ & $-4 \cdot 12$ & -0.89 & -0.38 & 0.02 & $0 \cdot 14$ & $0 \cdot 12$ & 0.50 & 0.07 \\
\hline DMD CalA & $\mathrm{Xp} 21.3-\mathrm{p} 21.1$ & $-x$ & -6.51 & -1.61 & -0.91 & -0.36 & -0.11 & 0.00 & 0.01 & 0.45 \\
\hline $\mathrm{DXS} 84 / \mathrm{L} 754$ & $\mathrm{Xp} 21.1$ & $-x$ & $-4 \cdot 35$ & -0.94 & -0.36 & $0 \cdot 11$ & 0.23 & $0 \cdot 18$ & 0.23 & 0.32 \\
\hline $\mathrm{DXS} 228 / 1 \mathrm{aA} 6 / 2(\mathrm{cA})$ & Xp11.4-p11.3 & 2.71 & $2 \cdot 70$ & $2 \cdot 49$ & $2 \cdot 25$ & 1.74 & $1 \cdot 17$ & 0.57 & $2 \cdot 71$ & 0.00 \\
\hline $\mathrm{MAO}-\mathrm{A} /(\mathrm{cA})$ & Xp11.4-p11.3 & 1.33 & $1 \cdot 32$ & 1.31 & $1 \cdot 29$ & $1 \cdot 10$ & 0.82 & 0.45 & 1.33 & 0.00 \\
\hline Awaited/RC12/(cA) & $\mathrm{Xp} 11.4-\mathrm{p} 11.23$ & 1.10 & $1 \cdot 10$ & 1.02 & 0.93 & 0.73 & 0.51 & $0 \cdot 27$ & $1 \cdot 10$ & 0.00 \\
\hline $\mathrm{DXS} 426 /(\mathrm{cA})$ & $\mathrm{Xp} 11.4-\mathrm{p} 11.23$ & 0.90 & 0.90 & 0.81 & 0.72 & $0 \cdot 52$ & 0.30 & $0 \cdot 09$ & 0.90 & 0.00 \\
\hline $\mathrm{PFC} /(\mathrm{cA})$ & $\mathrm{Xp11.4-p11.23}$ & 3.56 & 3.55 & $3 \cdot 20$ & $2 \cdot 85$ & $2 \cdot 12$ & 1.38 & $0 \cdot 66$ & 3.56 & 0.00 \\
\hline $\mathrm{DXS} 255 \mathrm{M} 27 \beta$ & $\mathrm{Xp} 11.21$ & $-x$ & $1 \cdot 46$ & 2.79 & $2 \cdot 70$ & $2 \cdot 20$ & 1.52 & $0 \cdot 76$ & $2 \cdot 79$ & 0.06 \\
\hline $\mathrm{DXS14} / \mathrm{p} 58.1$ & $\mathrm{Xp} 11.21$ & $-\infty$ & -0.36 & $1 \cdot 10$ & $1 \cdot 13$ & 0.88 & 0.48 & $0 \cdot 10$ & $1 \cdot 14$ & 0.08 \\
\hline $\mathrm{DXS} 453 /(\mathrm{cA})$ & $\mathrm{Xp11.23-q21.1}$ & $-x$ & $0 \cdot 12$ & 1.57 & 1.61 & $1 \cdot 36$ & 0.97 & 0.52 & 1.62 & 0.08 \\
\hline DXS566/N96(cA) & $\mathrm{Xq13}$ & $-x$ & $-4 \cdot 25$ & -0.94 & -0.42 & -0.02 & $0 \cdot 12$ & $0 \cdot 11$ & $0 \cdot 13$ & 0.35 \\
\hline $\mathrm{DXS} 456 /(\mathrm{cA})$ & $\mathrm{Xq} 21-\mathrm{q} 23$ & $-x$ & -8.89 & -2.25 & $-1 \cdot 18$ & -0.33 & -0.01 & $0 \cdot 06$ & 0.06 & $0 \cdot 40$ \\
\hline $\mathrm{DXS} 454 /(\mathrm{cA})$ & $\mathrm{Xq} 21.1-\mathrm{q} 23$ & $-x$ & $-5 \cdot 54$ & $-2 \cdot 10$ & -1.48 & -0.84 & -0.47 & -0.21 & 0.00 & 0.50 \\
\hline DXS42/p43-15 & $\mathrm{Xq} 25-\mathrm{q} 25$ & $-x$ & $-4 \cdot 25$ & -0.94 & -0.42 & -0.02 & $0 \cdot 12$ & $0 \cdot 11$ & $0 \cdot 13$ & 0.35 \\
\hline $\mathrm{DXS} 424(\mathrm{cA})$ & $\mathrm{Xq} 24-\mathrm{q} 26$ & $-x$ & -9.34 & -2.57 & -1.43 & -0.44 & -0.03 & 0.09 & 0.09 & 0.41 \\
\hline DXS52 ST-14 & $\mathrm{Xq} 28$ & $-x$ & $-10 \cdot 08$ & $-3 \cdot 23$ & $-2 \cdot 01$ & -0.87 & -0.33 & -0.07 & 0.00 & 0.50 \\
\hline
\end{tabular}

\section{Discussion}

The clinical information from our family shows evidence of a cone and rod dysfunction and has a number of common features with the previously reported examples of $\mathrm{AIED}^{235}$ and CSNB2. ${ }^{8}$

The essentially normal fundal appearance of our affected subjects is consistent with their skin and hair pigmentation. There is no evidence of albinism. One of our affected subjects did not have detectable nystagmus and another developed this sign between the ages of 15 and 23 years, consistent with the documenting of nystagmus in 11 out of 13 affected males by Rosenberg et $a l,{ }^{3}$ and in all the affected males from the original family of Elenius et al. ${ }^{2}$ The observation of Miyake et $a l^{\beta}$ that just $35 \%$ in their series of CSNB2 exhibited nystagmus suggests that less severe early visual deprivation exists for the CSNB2 entity. Nevertheless, nystagmus represents a non-specific loss of vision in early life, and therefore does not necessarily correlate with levels of visual function. The family that we have studied has provided the opportunity to examine their visual function from infancy to late adulthood (2 to 49 years) which differs from the essentially adult age group available to Elenius $e t a l^{2}$ and Rosenberg et $a l^{3}$ but is closely comparable to the age range studied in CSNB2. ${ }^{8}$ The records of previous ophthalmological assessments on IV 8 over some 20 years suggest that the condition shows progression throughout childhood until early adult life consistent with the retrospective information available to Rosenberg et al. ${ }^{3}$ It is possible that the decline in visual function seen in IV. 8 could be attributed to the increasing myopia alone as the result of normal growth in the first two decades of life but this seems less likely since the myopia in AIED is unaccompanied by signs of myopic degeneration of the fundus. ${ }^{235}$ The essentially stationary nature of the condition is consistent with AIED ${ }^{235}$ and CSNB2. ${ }^{8}$

All our affected subjects have significant myopia (ranging from $-30 \mathrm{D}$ to $-3 \mathrm{D}$ ) accompanied by astigmatism consistent with the findings in the original family. ${ }^{25}$ However, Rosenberg $e t a l^{3}$ found one affected male with near normal refraction and suggested that an age dependent transition from hyperopia to myopia may occur. In contrast in persons affected with CSNB2 the refractive error var- ies between mild myopia to hypermetropia ${ }^{8}$ and indeed the greater proportion may be hypermetropic. ${ }^{81113}$

In keeping with the two previous reports of AIED, ${ }^{23}$ and despite the subjective lack of awareness of nyctalopia, defective dark adaptation is present, together with preservation of the peripheral photopic visual fields. As comparisons of the dark adaptation curve show this adaptive process is very similar. ${ }^{23}$ A close match between our family, AIED, ${ }^{23}$ and $\mathrm{CSNB}^{8}$ is also apparent.

Comparisons of the scotopic ERG data in fig 1 show a near identical ERG appearance (Schubert-Bornschein type) with the previous AIED reports $^{23}$ and CSNB2 ${ }^{8}$ suggesting a similar level of rod system involvement between AIED, CSNB2, and our family.

Depressed, near extinct cone flicker responses in our affected subjects (fig 4) show great similarity to those recorded by Elenius et $a l^{2}$ and by Rosenberg $e t a l^{3}$ (fig 1). Although a significant reduction in the amplitude of the cone flicker responses was recorded in CSNB2 (mean $30 \mathrm{~Hz}$ flicker b wave amplitude, $11 \mu \mathrm{V}$ ) using a comparable method, ${ }^{8}$ this is a less severe diminution in cone function than our results (mean $30 \mathrm{~Hz}$ flicker b wave amplitude, $5 \mu \mathrm{V}$ ) indicate. The near complete loss (but not absence) of oscillatory potentials observed on the subnormal $b$ wave of the scotopic ERG from affected males in this family (fig 4) is of a very similar appearance to that published in the two earlier reports, ${ }^{23}$ as can be seen in fig 4 .

Rosenberg $e t a l^{\beta}$ interpret this as a 'preservation' of oscillatory potentials but all the oscillatory potentials illustrated appear to be markedly reduced to similar levels. However, this 'preservation' of the oscillatory potentials differs from the oscillatory potentials more often associated with the scotopic ERGs in CSNB $2,{ }^{8}$ in that those recorded from CSNB2 subjects show less accentuated reductions and very often approach a normal appearance. These comparisons imply that CSNB2 has a less severe cone involvement in the disease process than the AIED entity. Furthermore, differences in the diminution of oscillatory potentials observed between CSNB2 subjects suggests a range of severity exists for rod and cone system defects in CSNB2 at the level of the bipolar cells. Affected subjects from our family show a tritanomalous colour deficiency 
which is similar to that reported by Elenius et al. ${ }^{2}$ The mild red-green deficiency observed by Rosenberg $e t \mathrm{al}^{3}$ in their affected subjects may be explained by the bias of the screening tests used towards any colour vision defect being reported as a red-green defect. However, only about a third of CSNB2 subjects have a similar blue-yellow defect in colour vision, ${ }^{8}$ again indicating a less marked cone pathology for the CSNB2 entity.

In summary, we have presented a family in which affected males show reduced rod and cone function, and there are no clinical or subclinical carrier abnormalities. The features in our family are similar to the original AIED family ${ }^{25}$ and the second putative family, ${ }^{3}$ and the minor differences observed can probably be attributed to the different age groups studied. We confirm that the condition is of early onset and may be progressive until early adulthood, but then stabilises. There are many common features between our family, AIED, and CSNB2 which supports the original assertion by Krill' that AIED and CSNB2 are the same entity. However, variance between the conditions does exist in that nystagmus is much less frequently encountered in CSNB2 and that myopia is either absent or much less severe in CSNB2. Since the scotopic ERGs are essentially indistinguishable, ${ }^{12}$ and the dark adaptive processes appear to be nearly identical, a similar rod system defect appears to be present. This study suggests a less severe involvement of the cone system occurring in CSNB2 as cone specific electrophysiological investigations generally show a milder disturbance of function in CSNB2. If the conditions are indeed allelic then it appears that CSNB2 is a less severe form of the disease than AIED. The issue of whether CSNB2 and AIED are allelic may be addressed by molecular studies and in particular by observation of key recombination events.

Putative assignment of the gene responsible

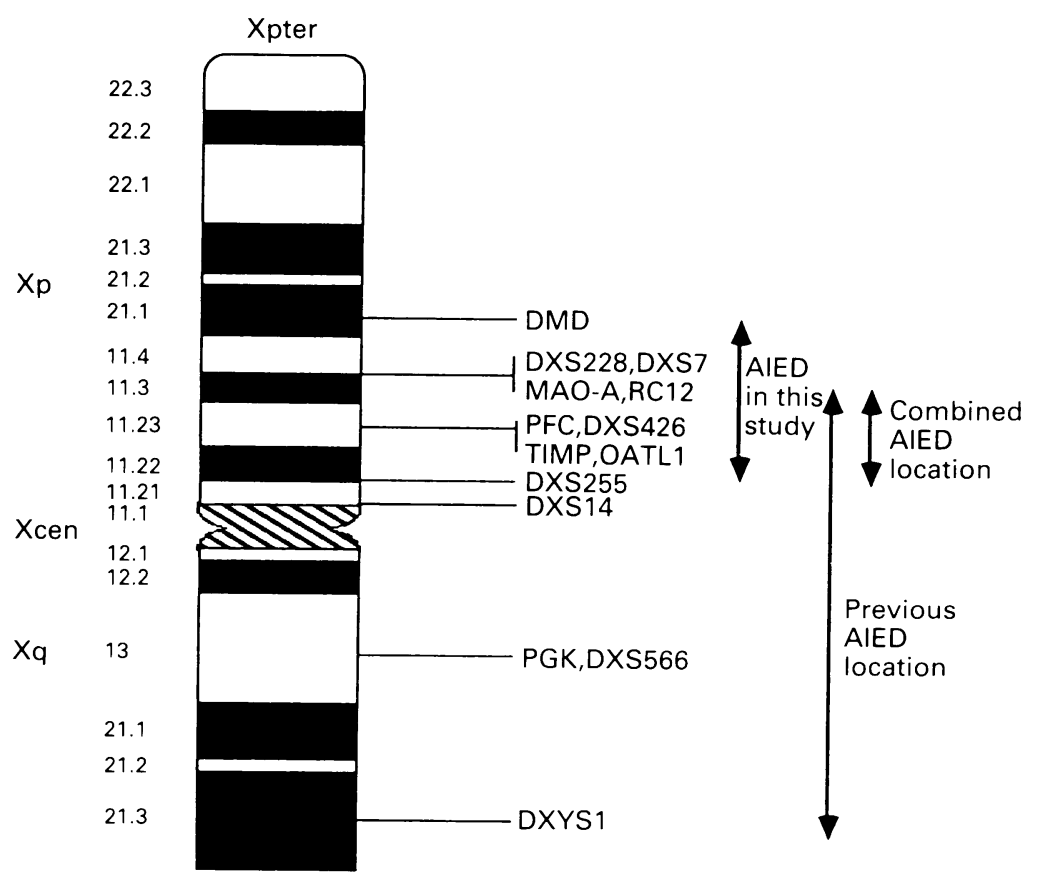

Figure 6 AIED gene location. for $\mathrm{AIED}$ was made to $\mathrm{Xp} 21$ following the report of a male with a contiguous gene deletion having a complex phenotype of Duchenne muscular dystrophy, glycerol kinase deficiency, congenital adrenal hypoplasia, and mental retardation. ${ }^{1225}$ In addition an eye disease was identified in this male characterised by congenital nystagmus, iris transillumination, fundal depigmentation, and a negative scotopic ERG with no rod component. ${ }^{2}$ However, the $30 \mathrm{~Hz}$ cone flicker response was of normal amplitude and the oscillatory potentials appeared normal. ${ }^{12}$ Although this subject was considered to be an example of AIED the closest match for the ERG features (in view of the preserved flicker responses) is CSNB2 or CSNB1. ${ }^{813}$ Moreover the lack of a rod component in the scotopic ERG argues against this being CSNB2 or AIED. The deletion mapping for this patient suggested the causative gene to be located within the interval DXS67DMD in Xp21.3-21.2.25 Recombination at DXS164, just $5^{\prime}$ to the limit of the deletion observed in their patient's DMD gene, ${ }^{25}$ was observed in the CSNB2 pedigree studied by Musarella et $a l^{13}$ suggesting these two conditions are distinct. No recombinants were observed with the Xp11 loci TIMP, DXS255, and DXS14 suggesting an Xp11 localisation for the CSNB2 gene. ${ }^{13}$

Linkage analysis of the original AIED family enabled a localisation for the gene to be made to pericentromeric $\mathrm{X}$, between DMD and PGK. ${ }^{20}$ In addition recombination at DMD precluded an Xp21 localisation for the gene in this pedigree ${ }^{26}$ suggesting either that AIED is genetically heterogeneous or more likely that AIED and the gene from the patient of Weleber et al ${ }^{12}$ are distinct. Assignment of AIED to between DMD and PGK was refined by the report of a second family that very closely resembled the features of the original AIED family. ${ }^{3}$ Localisation of the mutant gene to the interval DXS7-DXYS1 was made on the basis of phase known recombinant information. This study showed tight linkage to the Xp11 loci TIMP and DXS255 and again showed Xp21 recombination. ${ }^{27}$

Our family has clinical features consistent with that of the previous AIED reports ${ }^{235}$ and confirms tight linkage to Xp11 loci with no recombination observed with the loci DXS228 and PFC. ${ }^{28}$ Furthermore a localisation outside $\mathrm{Xp} 11$ appears unlikely as recombination is observed with loci derived from distal $\mathrm{Xp}$ and $\mathrm{Xq}$ (table 4). Phase known recombinations with DMD, DXS255, and the proximal Xq locus, DXS566, known to be closely linked to PGK in Xq13,22 are depicted in fig 2. These events suggest that the gene responsible for AIED is located within the DMD-DXS255 interval in our family. Moreover, since III.5 appears to be a carrier for the AIED gene, the recombination at DXS14 observed in her unaffected son IV.7 (confirmed as normal by ERG study, details available) supports a localisation for the gene distal to DXS255. ${ }^{29}$ Assuming unity for the three pedigrees, the combined localisation of AIED between DXS7-DXS255 is illustrated in fig 6 . 
The data on the genetic localisations of AIED and CSNB2 are as yet insufficient to clarify whether they are indeed allelic. A greater body of mapping data exists for CSNB1 in which many more families have been studied. Assignment of this locus to the $11 \mathrm{cM}$ interval (DXS228, DXS7, MAO-A, DXS7)-(DXS426, PFC, TIMP, OATL1) is suggested by Bech-Hansen et $a l^{30}$ and to the TIMP-OTC interval by $\mathrm{Li}$ et al. ${ }^{31}$ However, the recent observation of recombination between CSNB1 and DXS732 orients CSNB1 proximal to DXS7, and thus the question of allelism between AIED/CSNB2 and CSNB1, on the basis of genetic mapping information, remains open.

The authors are very grateful to Professor James Crews for critical discussions and to the family for their willing cooperation. This work was supported by the British Retinitis Pigmentosa Society (MPC, PF) and the Medical Research Council of Great Britain (AHN, KED).

1 Krill A. Congenital stationary night blindness. In: Krill's hereditary retinal and choroidal diseases. Vol II. Hagershereditary retinal and choroidal diseases.

2 town: Harper and Row, $1977: 391-420$. chromosomal pigment deficiency of fundus in combination with myopia, dyschromatopsia and defective dark-adaption. In: The clinical value of electroretingraphy. Karger, 1968:369-77.

3 Rosenberg T, Schwartz M, Simonsen SE. Aland eye disease (Forsius Eriksson-Miyake syndrome) with probability established in a Danish family. Acta Ophthalmo 1990;68:281-91.

4 Van Dorp DB, Eriksson AW, Dellman JW, et al. Aland eye disease: no albino misrouting. Clin Genet 1985;28:526-31.

5 Waardenberg PJ. Some notes on publications of Professor Arnold Sor Arnold Sorsby and on Aland eye disease (For

son syndrome). f Med Genet 1970;7:194-9.
van Vliet AGM, Waardenberg PJ, Forsius HR, Eriksson AW. Nystagmographical studies in Aland eye disease. Acta Ophthalmol 1973;51:782-90.

7 Jacobson DM, Thompson HS, Bartley JA. X-linked progressive cone dystrophy. Clinical characteristics of affected males and carriers. Ophthalmology 1989;96:885-95.

8 Miyake Y, Yagasaki K, Horiguchi M, Kawase Y, Kanda T. Congenital stationary night blindness with negative electroretinogram. A new classification. Arch Ophthalmo 1986;104:1013-20.

9 Pearce WG, Bech-Hansen NT. Gene locus for X-linked CSNB Genomics 1990;8:743-8.

10 Musarella M. Gene locus for X-linked CSNB (response). Genomics 1990:8:743-4.

11 Khouri G Mets MB, Smith VC, Wendell M, Pass AS. Xlinked congenital stationary night blindness. Arch Ophthalmol 1988;106:1417-22.

12 What RE, Buist NRM. Aland Island eye disease (Forsius-
Ericksson syndrome) associated with contiguous deletion syndrome at Xp21. Arch Ophthalmol 1989;107:1170-9.

3 Musarella MA, Weleber RG, Murphey WH, et al. Assignment of the gene for complete X-linked congenital stationary night blindness (CSNB1) to Xpl1.3. Genomics 1989;5:727-37.

14 Gal A, Schinzelm A, Ulrike O, et al. Gene of X-chromoso( mal congenital stationary night blindness is clo.

15 Bech-Hansen NT, Field LL, Schramm AM, et al. A locus for X-linked congenital stationary night blindness is for X-linked congenital stationary night blindness is located on the proximal portion of the short

6 Apkarian P, Reits D, Spekreijse H, van Dorp D. A decisive electrophysiological test for human albinism. Electroenceph Clin Neurophysiol 1983;55:513-31.

17 Kunkel LM, Smith KD, Boyer SH, et al. Analysis of human $\mathrm{Y}$ chromosome-specific reiterated DNA in chromosome variants. Proc Natl Acad Sci USA 1977;74:1245-9.

18 Glass IA, White EM, Pope MJ, Pirrit L, Cockburn F, Connor JM. Linkage analysis in a large family with nonspecific XLMR. Am ₹ Med Genet 1990;38:298-304.

19 Saiki RK, Scharf S, Faloona F, et al. Enzymatic amplification of beta globin sequences and restriction site analysis tion of beta globin sequences and anaemia. Science 1985; for diagno: $1350-4$.

20 Weber JL, May PE. Abundant class of human DNA polymorphisms which can be typed using the polymerase polymorphisms which can be typed using the poly

21 Whain reaction. Am $f$ Hum Genet $\mathrm{K}$, et al. Report of the Williamson $\mathrm{R}$, Bowcock $\mathrm{A}$, Kidd $\mathrm{K}$, et al. Report of the
DNA committee and catalogues of cloned and mapped genes, markers formatted for PCR and DNA polymorphisms. HGM11. Cytogenet Cell Genet 1991;58:1190832

22 Lindsay S, Curtis ARJ, Roustan P, Kamakari S, Thiselton DL, Bhattacharya SS. Isolation and characterisation of 3 microsatellite markers in the proximal long arm of the human X chromosome. Genomics 1993;17:208-10.

23 Attwood J, Bryant S. A computer program to make linkage analysis with LIPED and LINKAGE easier to perform analysis with LIPED anu Genet and less; $52: 259$.

24 Ott J. Estimation of the recombination fraction in human pedigrees: efficient computation of the likelihood for

25 Pillers DM, Towbin JA, Chamberlain JS, et al. Deletion mapping of Aland Island eye disease to $\mathrm{Xp} 21$ between DXS67 (B24) and Duchenne muscular dystrophy. $A m \mathcal{F}$ Hum Genet 1990;47:795-801.

26 Alitalo T, Kruse TA, Forsius H, Eriksson AA, de la Chapelle A. Localization of the Aland Island eye disease locus to the pericentromeric region of the $\mathrm{X}$ chromosome by linkage analysis. Am f Hum Genet 1991;48:31-8.

27 Schwartz M, Rosenberg T. Aland eye disease: linkage data. Genomics 1991:10:327-32.

28 Coleman MP, Murray JC, Willard HF, et al. Genetic and physical mapping around the properdin $\mathrm{P}$ gene. Genomics 1991;11:991-6.

29 Mahtani MM, Lafreniere RG, Kruse TA, Willard HF. An 18-locus linkage map of the pericentromeric region of the human X chromosome: genetic framework for mapping human X chromosome: genetic framework for

30 Bech-Hed disord, Mrell KJ, Moore BJ, et al. Localisation of CSNB1 to region Xp11.3-Xp11.23 between MAO tion of CSNB1 to region Xp11.3-Xp11.23 between MAO $1991 ; 58: 216$.

31 Li Y, Bleeker-Wagemakeers E, Artlich A, et al. The locus for X-chromosomal congenital stationary night blindness is closely linked to timp in two families but not in a third one. HGM11. Cytogenet Cell Genet 1991;58:235-6.

32 Bech-Hansen NT, Moore BJ, Pearce WG. Mapping of locus for X-linked congenital stationary night blindnes (CSNB1) proximal to DXS7. Genomics 1992;12:409-11. 